
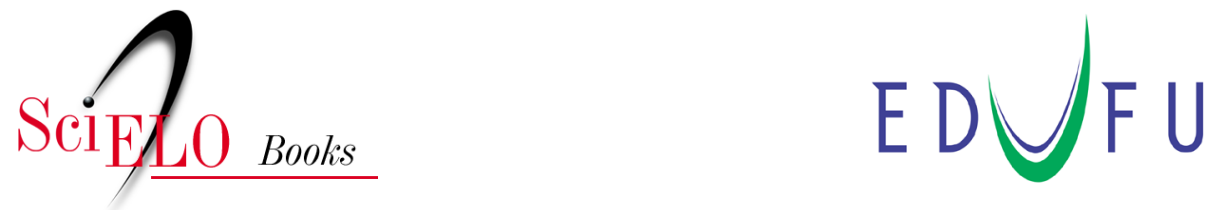

\title{
O laço na escrita em textos acadêmicos um estudo enunciativo
}

\author{
Jorama de Quadros Stein \\ Marlene Teixeira
}

\section{SciELO Books / SciELO Livros / SciELO Libros}

STEIN, J.Q., and TEIXEIRA, M. O laço na escrita em textos acadêmicos: um estudo enunciativo. In: AGUSTINI, C., and ERNESTO, B., eds. Incursões na escrita acadêmico-universitária: letramento, discurso, enunciação [online]. Uberlândia: EDUFU, 2017, pp. 73-92. ISBN: 978-65-86084-26-9.

https://doi.org/10.7476/9786586084269.0005.

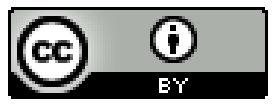

All the contents of this work, except where otherwise noted, is licensed under a Creative Commons Attribution 4.0 International license.

Todo o conteúdo deste trabalho, exceto quando houver ressalva, é publicado sob a licença Creative Commons Atribição 4.0. 


\section{O laço na escrita em textos acadêmicos: um estudo enunciativo}

Jorama de Quadros Stein

Marlene Teixeira

\section{Palavras iniciais}

Esta reflexão decorre do trabalho apresentado no IV Simpósio Internacional de Ensino de Língua Portuguesa - Sielp, ${ }^{1}$ no Grupo de Trabalho - GT A escritura acadêmica no processo de assunção ao discurso acadêmico. Partimos da preocupação em estudar o processo de escrita em textos acadêmicos com foco na configuração do laço entre professorrevisor e aluno-scriptor. ${ }^{2}$ Convidamos o leitor a buscar em Benveniste formulações essenciais para pensar sobre a escrita de forma a concebê-la como indissociável da relação entre aquele que escreve e aquele que lê ou revisa o texto.

${ }^{1}$ O GT foi coordenado pela Profa. Dra. Carmen Agustini (UFU) e pelo Prof. Dr. Ernesto Bertoldo (UFU), em Uberlândia-MG. A eles, eu, Jorama de Quadros Stein, agradeço pela acolhida, pela partilha e pelo convite para trazer para a escrita uma reflexão a partir da comunicação oral realizada. À minha orientadora, toda a minha gratidão pela interlocução ofertada para a qualificação deste estudo e por fazer comigo um laço muito além do âmbito acadêmico, um laço que ressignifica a forma com que olho para mim, para esta escrita e para minha prática como professora.

${ }^{2}$ Scriptor, para nós, designa aquele que escreve, que se diferencia do autor. É a tradução do termo scripteur, utilizado por geneticistas do texto como Irène Fenoglio (2011). 
Para elucidarmos as formulações que nos permitem pensar na escrita por/com/em Benveniste, partimos de alguns princípios básicos: a) o homem está na língua; b) o sujeito é um ponto de chegada; c) sem tu não há eu; d) a escrita é a cada vez uma re $e^{3}$-invenção. Os pontos, por ora somente elencados, serão discutidos a seguir e mais adiante sustentados através da apresentação de uma resenha acadêmica, produzida em duas versões, a qual integra o corpus de textos que constitui o material de investigação da tese da qual parte este estudo. ${ }^{4}$

\section{O sujeito aos pés de um tu}

O sujeito, durante algum tempo, foi excluído dos estudos linguísticos. Tratar do sujeito era ter de enfrentar a "cabeça de medusa", para utilizar a expressão de Benveniste para se referir ao estudo do sentido. Deixávamos para a filosofia e para a psicologia essa preocupação e nós, da linguística, nos dedicávamos a estudar a linguagem dissociada do sujeito, porém, com o tempo, irremediavelmente, o sujeito clamou por espaço em nossas pesquisas. Afinal de contas, se há linguagem, há um locutor que se instaura nela e que se implica subjetivamente em seu dizer.

Charles Bally, linguista francês, que se dedicou ao estudo da língua e da literatura clássica, começou a se perguntar sobre a subjetividade na linguagem. Mais tarde, Benveniste, linguista sírio, naturalizado francês, que se dedicou ao estudo aprofundado de diversas línguas e, ao mesmo tempo, ao desenvolvimento de uma teoria enunciativa da linguagem, continuaria a problematizar essa questão por tratar homem e língua(gem) como indissociáveis. Nesse contexto, Benveniste sustentou, como bem sabemos, que a intersubjetividade é condição para a subjetividade, pensamento sintetizado, a priori, no texto Da subjetividade na linguagem, de 1958

\footnotetext{
${ }^{3}$ Separamos o prefixo -re do restante da palavra para assumirmos, em nosso relato, a perspectiva benvenistiana, uma vez que para Benveniste (2005d, p.26), “a linguagem reproduz a realidade. Isso deve entender-se da maneira mais literal: a realidade é produzida novamente por intermédio da linguagem". 0 re, em itálico no original em francês, enaltece a crença que perpassa as formulações de Benveniste ao longo de seus textos: o novo a cada enunciação, isto é, neste caso, a linguagem produz sempre de maneira nova a realidade.

${ }^{4}$ Usamos "da tese da qual parte este estudo" para definirmos que nos referimos à parte do corpus da tese em curso de Jorama Stein, uma das autoras deste trabalho. A co-autora, como orientadora, contribui com apontamentos e reflexões fundamentais para a discussão aqui proposta.
} 
(2005b), e que se constitui em uma premissa para compreender duas coisas no autor: que só há enunciação mediante um tu, postulado como alocutário, e que é somente a partir deste tu que é possível observarmos o sujeito.

Logo, compreender o sujeito na teoria da enunciação é fundamental. Normand (2009) salienta a flutuação do termo em Benveniste. A expressão aparece grafada de diversas maneiras, como em itálico ou entre aspas e às vezes como sinônimo de locutor ou indivíduo. A linguista esclarece, ainda, que é preciso compreender que o sintagma sujeito do enunciado e sujeito da enunciação não aparece em Benveniste.

Flores (2013) explica que o sujeito da enunciação é o que advém da sintaxe da enunciação e sua existência está ligada ao fato de atribuirmos ao conjunto das formulações de Benveniste o estatuto de linguística da enunciação. Dessons (2006), por sua vez, assegura que a noção de discurso preencheu, de certa forma, a falta do sujeito. É um ponto bem importante, afinal de contas, o discurso pressupõe uma atividade de linguagem do homem.

Instaurou-se, aos poucos, uma linguística que não pode deixar o homem de lado porque faz ciência sobre um homem que está sempre se enunciando. 0 locutor, que, contudo, se instaura na linguagem, não é o sujeito. 0 sujeito advém do que foi dito, mas não do que está estanque no enunciado. Advém dos encadeamentos, da enunciação em si. Advém não somente dos índices específicos, mas também dos procedimentos acessórios $^{5}$. Só que não podemos apreendê-lo em sua totalidade e, por isso, cabe a nós buscar a compreensão dos agenciamentos sintagmáticos para saber qual sujeito emerge de cada instância de enunciação.

Por isso Capt (2013) tem muita razão ao distanciar o sujeito da enunciação das concepções metafísicas. 0 linguista francês mostra que o sujeito da psicologia e de vertentes pragmático-comunicacionais da linguística nada tem a ver com o sujeito benvenistiano, pois o último é um "ponto de chegada" (Capt, 2013, p.82) e não um ponto de partida. Ele assegura a transitividade, a incompletude e a dependência do sujeito do linguista sírio: "Assim considerado, o sujeito é transitivo, sempre sujeito 'de alguma coisa'. Ele não é autossuficiente. Ele não é autônomo. Ele é incompleto. Ele depende do outro" (Capt, 2013, p.78, tradução nossa).

\footnotetext{
${ }^{5}$ Para uma compreensão do jogo entre índices específicos e procedimentos acessórios na análise enunciativa benvenistiana, conferir: ARESI, F. Os índices específicos e os procedimentos acessórios da enunciação. ReVEL, v.9, n.16, 2011.
} 
Trata-se, portanto, de um sujeito que não emerge se não houver um outro que o autorize a ser sujeito. Só nos tornamos sujeitos ao falar porque somos reconhecidos como tal ao fazê-lo: "o sujeito que nós conservamos na linguagem possui uma descontinuidade permanente, uma historicidade radical, uma plasticidade constitutiva. Um sujeito em constante recomeço, um sujeito aos pés de um 'tu'”' (Capt, 2013, p.79, tradução nossa).

Quando problematizamos a escrita, uma complexidade se instaura, pois, precisamos pensar sobre o sujeito. 0 alocutário, postulado pelo scriptor, nem sempre é consciente e nem sempre pode estabelecer uma comunicação intersubjetiva de fato. E aí é preciso um olhar aguçado sobre os encadeamentos, sobre as escolhas daquele que escreve para que percebamos que sentidos emergem e qual sujeito advém.

Ao observarmos as diferentes versões de um texto, com as interferências da revisão do professor, podemos investigar os sentidos que se reestabelecem e é aí que podemos fazer uma linguística atenta ao homem que se renova a cada vez que se enuncia. Para tanto, é bem importante a experiência de atentarmos para a escrita se materializando, se fabricando, a exemplo dos trabalhos que são objetos de estudo da linguista geneticista Irène Fenoglio.

Não queremos com isso excluir a relevância do estudo da versão final do texto. Queremos ver, no processo, uma alavanca propulsora para compreender mais e melhor os sentidos e o sujeito de uma escrita. E mais: encaramos o professor como um problematizador que, ao realizar uma revisão que configure troca no processo, possa de fato auxiliar os seus alunos a deslocar o endereçamento de seus textos para outros leitores. Para isso, é preciso discutir mais sobre o sentido na escrita, pois é mais uma chave para o trabalho com o texto.

\section{Sentido na enunciação}

Para tratarmos do sentido em Benveniste com enfoque na escrita, é preciso atentar para o que o linguista sugere ao final do artigo $O$ aparelho formal da enunciação (Benveniste, 2006c), no qual ele abre a possibilidade de estudarmos as formas complexas do discurso:

Será preciso também distinguir a enunciação falada da escrita. Esta se situa em dois planos: o que escreve se enuncia ao escrever e, no interior de sua 
escrita, ele faz os indivíduos se enunciarem. Amplas perspectivas se abrem para a análise das formas complexas do discurso, a partir do quadro formal esboçado até aqui(Benveniste, 2006c, p.90, grifos nossos).

Anteriormente, no final de Semiologia da língua (Benveniste, 2006d), o autor propõe que ultrapassemos a noção saussuriana de signo e que o façamos de duas maneiras: por uma análise intralinguística ou por uma análise translinguística. A última é que nos permite investigar textos e obras e pressupõe a elaboração de uma metassemântica que se constituirá sobre a semântica da enunciação.

Flores e Teixeira (2013) tratam sobre essa proposição benvenistiana de estudarmos as formas complexas do discurso e explicam a amplitude desse convite: fazer uma linguística que olhe para os textos, as obras, a arte. Eles salientam que Benveniste não chegou a evidenciar a maneira de concretizar a segunda via da semiologia, embora suas formulações tragam subsídios para tal. Os autores acentuam a relevância da problematização da escrita em Dernières Leçons (Benveniste, 2012) como um passo do linguista sírio na abordagem dessas formas.

A escrita para Benveniste é, portanto, uma forma complexa do discurso que, como ele mesmo formulava na obra publicada em 2012, pressupõe uma série de abstrações e toma um dimensionamento que a afasta de mera representação da fala. Da lição 8 até a 15, temos um Benveniste professor, como bem lembram Agustini et al (2013). Trata-se de um professor que discute o semiótico e o semântico partindo do estudo de diferentes línguas a fim de problematizar o lugar da escrita entre os sistemas.

É nessa publicação que Benveniste esclarece que, se a língua é dotada de dupla significância, a escrita é a prova disso. Logo, é quase impossível pensar sobre a escrita sem compreender bem como Benveniste concebe o semiótico e o semântico. Sabemos que muito se ouve acerca da significação desses termos. Por ora, e para os propósitos desta reflexão, sintetizamos o que nos parece mais caro no emprego dos termos em Benveniste: ambos são constituídos por forma e por sentido.

A preocupação de Benveniste é unir forma e sentido tanto no nível formal quanto no discurso. No semiótico, a forma é o significante e o sentido a capacidade de ser distinguido no sistema."Significar é ter um sentido, nada mais" (Benveniste, 2006a, p.277). Nesse nível, "ser distintivo e ser significativo é a mesma coisa” (Benveniste, 2006a, p.28). 
No semântico, a forma é constituída pela sintagmatização e o sentido pela referência coconstruída, pela ideia. 0 "mundo" é subjetivado na cultura. É um mundo construído pelo locutor que se apropria da língua e que é redimensionado pelo $t u$, na interlocução. Nesse sentido, é da vida da linguagem não ter condição de expressar o mundo tal como é porque entre o semiótico e o semântico há um locutor que se apropria da língua, mas que leva consigo os tantos outros nele implicados.

Flores (2013) elucida bem que,ao tratarmos do sentido em Benveniste, temos dois questionamentos para nortear nossos estudos. Quando consideramos o semiótico, o sentido está no nível da designação e, portanto, é preciso perguntar se há ou não há sentido, bem na acepção saussuriana do termo: uma coisa é aquilo que a outra não é. Isso Benveniste faz ao dar o exemplo: "Chapéu existe? Sim. Chaméu existe? Não" (Benveniste, 2006a, p.227). Já no semântico, a pergunta é: qual é o sentido? Ou seja:

A noção de semântica nos introduz no domínio da língua em emprego e ação; vemos desta vez na língua sua função mediadora entre o homem e o homem, entre o homem e o mundo [...] impondo a adesão, suscitando uma resposta[...] em resumo, organizando toda a vida dos homens (Benveniste, 2006a, p.229).

Mello (2012) sintetiza bem a compreensão do sentido em Benveniste ao esclarecer que a frase, por ser particular, é um acontecimento que desaparece porque os sentidos se ressignificam a cada vez.

Benveniste propôs que pensássemos em uma semiologia de segunda geração para tratar da escrita, justamente pela sua distinção em relação à fala. Acreditamos, porém, que os subsídios para tal já estão nas formulações que ele realiza ao longo de seus estudos, questão que não será trazida neste texto, pois mereceria mais aprofundamento. Por ora, somente ressaltamos que a semiologia de Benveniste é baseada na enunciação e no discurso, por isso que é uma semiologia de segunda geração.

O que propomos é nos apropriarmos da proposta benvenistiana à medida que estudamos a configuração do laço no processo de escrita. Tratemos um pouco mais do laço. 


\section{O laço no processo de escrita: uma chave metodológica}

O sentido que emerge da escrita é sempre novo a cada versão de um texto. Essa afirmação corresponde à singularidade inerente a cada ato enunciativo, conforme a proposição de Benveniste. E só é possível pensarmos no sentido porque há um "homem na língua”, que se instaura a cada vez que o locutor se propõe como eu e o faz sempre de maneira nova, como o próprio Benveniste constatou ao estudar diversas línguas.

Se única é a condição do homem na linguagem, essa singularidade deve ser cuidadosamente estudada ao tratarmos do processo de escrita. Encontramos, nas formulações de Benveniste, suporte para investigar cada uma das versões de um texto como um espaço singular de enunciação.

Já sabemos que o sentido que emerge diz do sujeito. Esse sujeito, a posteriori, nos obriga a lembrar que aquele que emerge na escrita pode não ser o mesmo que emerge na relação em sala de aula. Mas reconhecemos que uma relação de troca desencadeadora de aprendizagem no dia a dia das aulas pode contribuir para sustentar uma troca de fato na relação da escrita.

Se temos uma escrita em processo, temos uma relação nessa escrita a ser observada. A observação da existência ou não de troca nessa escrita tem seu ponto de partida no estudo dos pronomes em Benveniste, pois é somente a partir dos índices eu-tu que podemos tratar do laço na escrita. Acreditamos, como afirma Teixeira (2012), que no estudo dos pronomes em Benveniste há um projeto de uma ciência geral do homem: "tenho proposto o deslocamento da interpretação que a restringe ao estudo das marcas da subjetividade na linguagem no âmbito intralinguístico, na direção das atividades significantes dos homens em qualquer tipo de interação social" (Teixeira, 2012, p.72).

Em textos como A natureza dos pronomes, de 1956 (2005a) e Estrutura das relações de pessoa no verbo, de 1946 (2005c), Benveniste trilha um caminho de 10 anos, que faz com que estenda a discussão dos pronomes para além da categoria gramatical. Mostra a assimetria entre eu-tu-ele. Embora no primeiro artigo, o eu ganhe destaque explícito, no segundo eu-tu são problematizados como posições na linguagem.

É em Da Subjetividade na linguagem, de 1958, que fica mais evidente o caráter antropológico do estudo de Benveniste: "É um homem falando que encontramos no mundo, um homem falando com outro homem, e 
a linguagem ensina a própria definição do homem" (Benveniste, 2005b, p.285). E continua: "A consciência de si mesmo só é possível se experimentada por contraste. Eu não emprego eu a não ser dirigindo-me a alguém, que será na minha alocução um tu" (Benveniste, 2005b, p.286, grifos nossos).

A afirmação em destaque sustenta a leitura que Capt (2013) faz do sujeito em Benveniste como um ponto de chegada, sempre sujeito de algo e insuficiente a si mesmo. Esse sujeito só emerge porque há um $t u$. Sem o tu não há eu.

Dufour (2000) leva-nos a problematizar a instanciação do quadro figurativo aluno-scriptor e professor-revisor tomando a abordagem dos pronomes em Benveniste em uma dimensão mais antropológica:

Quando um sujeito fala, ele diz "eu" a um "tu" a propósito d' "ele". Falem e porão em jogo este sistema e, a partir de então, um fantástico ordenamento do discurso será instantaneamente efetuado. Poderei realmente dizer o que quiser [...] desde que eu enuncie para um "tu” (um leitor, também), meu discurso vai apresentar as garantias implicitamente requisitadas por todo interlocutor" (Dufour, 2000, p.69, grifos do autor).

Araújo (2014) evidencia que toda enunciação pressupõe endereçamento de um eu a um $t u$, mas que nem sempre ocorre a troca entre os interlocutores. Ela sustenta que o endereçamento diverge da alocução propriamente dita, em que um falante apenas se dirige ao outro. 0 endereçamento, de acordo com a autora, além de projetar os participantes dessa alocução, via representação, circunscreve a possibilidade de essa projeção não se efetivar de modo a converter a língua em discurso no ato de linguagem que o produz.

Nesse sentido, Rocha (2014), baseada na ideia que a intersubjetividade é condição para a comunicação intersubjetiva, sustenta que, se para haver comunicação intersubjetiva, é preciso troca, ela só é possível pelo tu, logo o laço, de que tratamos aqui, só acontece se houver troca.

Para Araújo (2014), o laço corresponde à relação dialógica em que o $e u$, ao se endereçar a um $t u$, implica-se subjetivamente. Para ela, é fundamental o estabelecimento do processo de correferenciação entre os interlocutores porque assim é produzido o efeito pragmático da troca. Nesse sentido, podemos dizer que comunicação intersubjetiva e laço não são conceitos que se recobrem, mas sim que o primeiro é ponto de partida para o segundo. 
Nós podemos afirmar, assim, que o laço pode ser fundamentado a partir da teoria dos pronomes e do conceito de intersubjetividade em Benveniste, mas jamais pode ser bem concebido se não tivermos clareza da concepção benvenistiana de sujeito. 0 laço em Benveniste pode ser melhor compreendido se tomarmos sua teoria em uma dimensão antropológica. Assim como o sujeito benvenistiano só é possível na e pela linguagem, o laço também é observável no/pelo processo de escrita. 0 laço tem, portanto, uma dimensão incapturável porque advém da experiência única entre o aluno-scriptor e o professor-revisor. 0 laço, tal como estudamos aqui, é dimensionado em um olhar sobre o processo de enunciação, logo é complexo de ser observado.

Vejamos o que diz A linguagem e a experiência humana (1965), um dos textos que mais tem sustentado reflexões para projetar os estudos de Benveniste para além da linguística:

Desde que o pronome eu aparece num enunciado, evocando - explicitamente ou não - o pronome tu para se opor conjuntamente a ele, uma experiência humana se instaura de novo e revela o instrumento lingüístico que a funda. Mede-se por aí a distância, ao mesmo tempo ínfima e imensa, entre o dado e sua função. Estes pronomes existem, consignados e ensinados nas gramáticas, ofertados como os outros signos e igualmente disponíveis. Quando alguém os pronuncia, este alguém os assume, e o pronome eu, de elemento de um paradigma, se transforma em uma designação única e produz, a cada vez, uma nova pessoa. Esta é a atualização de uma experiência essencial, que não se concebe possa faltar a uma língua (Benveniste, 2006b, p.69, grifos nossos).

Propomo-nos, portanto, a olhar para a escrita enquanto reveladora da experiência humana. Essa proposição nos exige um trabalho cuidadoso para o processo em que o eu se instaura diante de um tu. Esse texto de 1965 aborda a temporalidade linguística, fundada no discurso. Podemos dizer que há algo a ser transposto para o estudo da escrita: um outro sistema, que exige outra organização do homem à medida que ele se reposiciona em seu discurso e em que a intersubjetividade é reiterada como o estopim para a troca:

A intersubjetividade tem assim sua temporalidade, seus termos, suas dimensões. Por aí se reflete na língua a experiência de uma relação primor- 
dial, constante, indefinidamente reversível, entre o falante e seu parceiro. Em última análise, é sempre ao ato de fala no processo de troca que remete a experiência humana inscrita na linguagem (Benveniste, 2006b [1965], p.80, grifo do autor).

Consideramos que é no processo de troca na escrita que se instaura/ registra uma experiência humana e é somente quando analisamos todo o processo que é possível redimensionar junto ao aluno de tal forma a sua escrita a ponto de convidá-lo a re-inventar a sua relação com ela. É através da relevância que damos ao processo, que podemos ressignificar a compreensão da re-escrita na escola e na universidade.

É a partir de uma reflexão sobre o laço em uma dimensão antropológica da linguagem, que configuramos, ainda que, por ora, parcialmente, nossa metodologia de análise.

Trata-se de um corpus de 10 textos de alunos universitários de diferentes cursos (todos, com, no mínimo, duas versões). Desses, foram escolhidos dois, os quais sofreram uma interferência mais marcada da professora. No entanto, aqui, apresentamos o exemplo de um dos textos.

Há uma particularidade na análise do corpus de pesquisa: como observamos a singularidade de cada escrita, não tomamos esse conjunto de textos como um produto acabado. Filiamo-nos ao estudo de Nunes (2012) para olhar esses textos considerando a singularidade do locutor e a unicidade de cada ato enunciativo. Assim, com base em Benveniste, consideramos a impossibilidade de delimitar uma unidade de análise como a priori de nossa investigação justamente por não ser o enunciado em si, mas a enunciação o nosso objeto.

Nesse sentido, não utilizamos o material de análise para corroborar uma hipótese prévia porque isso iria na contramão de nosso entendimento a respeito de sujeito e de sentido em Benveniste. Nunes (2012) ressalta que o analista tem um corpus de dados, mas que ao decidir quais aspectos serão analisados, ele imprime um recorte. 0 recorte em nossa análise está na configuração do laço entre professor-revisor e aluno-scriptor.

De acordo com essa visão, neste estudo, delimitamos nosso enfoque em dois pontos: descrever os movimentos realizados pelo aluno a partir da interferência da professora conforme as categorias da crítica genética e discutir algumas implicações da observação desses movimentos para a compreensão do laço. 


\title{
Um olhar para o processo de escrita
}

0 texto que apresentamos é composto por duas páginas em cada versão. Começamos apresentando a primeira página da primeira versão do texto analisado junto da primeira página da segunda versão. Em seguida, os movimentos realizados pela aluna são apresentados. Trata-se de um relato que evidencia o que o aluno faz a partir da interferência do professor em seu texto. Após, trazemos a segunda página de cada uma das versões em comparação uma com a outra. Esse registro constitui um dos primeiros passos para uma futura análise mais detalhada.

Atividade Acadbmica: Experimentacblo Textual - Horário 22 Aula de 18.11.2013: Claborando uma resenha academica

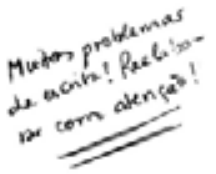
Bullying: prevalência, implicaçōes e diferenças entre os
gêneros.

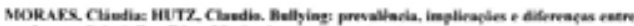

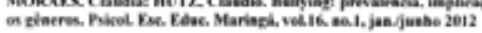

\begin{abstract}
O bufying se caracteriza pelo evidente proposito de humihar e prejudicar a vitimpé um comportamento facimente visto nas escoijg Sendo praticado tamto por meninos Quanko por meninas. A vitima of bullying é aquela cranca $/$ / $<A$ constantemente agredida pelos colegas e tem aficuldade de cessar ou reagir aos atacues.

O artigo Aullying: prevallncia, implicacōes e dferenças entre os gêneros, de autoria da psicóloga Clbudia Moraes, doutoranda da UFRGS e do professor Claudio Hutz, thular do departamento de psicologia da UFRGS, fol recentemente publicado pela revista Psucologia Escolar-e Foucacionai. 0 estudo teve como objetivo levantar a ccorréncia do bullying jem crianças e adolescentes de escolas do munidipio de Porto Alegre (KS).

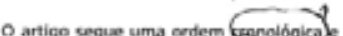

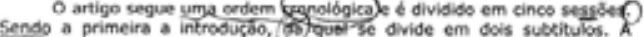
seguir, a segunda sesslo traz o metodo de pesquisa, tambem abordado em dois subtitulos: os instrumentos e os procedimentos utilizados. Na terceira sessajo sho trazidos es resultudos da pesquisa, que slio demonstrados $\mathrm{cm}$

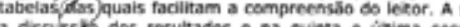
a discuscio dos resultados ef na guinea e útima sessbojo, podemos ler as consideraç̋̃es finais dos autorks.
\end{abstract}

Na introduclo do artigo, os autores usam referêneias bibliogrbficas 6 ara explicar (0)ro jo kitor sobre o gue se trata o bullying. No primeiro

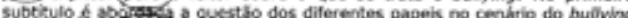

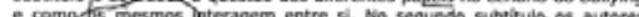
trazem in -diferencins entre os gêneros, no qual explicam bs tipos de \& agressdes mais usadas por cada ginera. 7

Na proxima sesslo é explicado syze ó método de pescuisa utilizado.

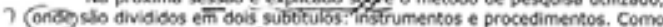
ingriumente de pespuisa? é euplicade gue os alunos utilizaram um questiondrio; e sobre os procedimentos, e csciarecido algumas questies cancardin.

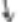
Concetor inade persto! Rever esine hes as tatibe

Versão 1- página1 
Atividade Acadêmica: Experimentaçắ Textual - Horário 22 Aula de 18.11.2013: Elaborando uma resenha acadêmica

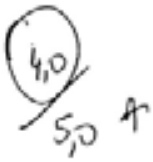

Bullying: prevalência, implicações e diferenças entre os gêneros.

MORAES, Claiedia; HUTZ, Claudio, Bullying: prevaltacis, implicaç̋es e diferenças entr es gketeres. Pricel. Eas. Edue. Mariezi, vol.16, no.1, jan.Juabs 2012

o bullying sefcaracteriza pelo evidente propósito de humilhar e prejudicar a vitimg: um comportamento facilmente visto nas escolas, sendo praticado tornto por meninos quanto por meninas. A vitima de bullying é aquela criança constantemente agredida pelos colegas e tem dificuldade de cessar ou reagir aos ataques.

O artigo Bullying: prevalência, implicaçōes e diferenças entre os gêneros, de autoria da psicóloga Cláudia Moraes, doutoranda da UFRGS e do professor Claudio Hutz, titular do departamento de psicologia da UFRGS. foi recentemente publicado pela revista Psicologia Escolar e Educacional. O estudo teve como objetivo levantar a ocorrênda do bullying em crianças e adolescentes de escolas do município de Porto Alegre (RS).

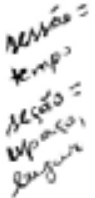

0 artigo é dividido em cinco sesçổes.

a qual se divide em dois subtho sessoes, sendo a primeira a introdução, metodo de pesquisa, tambem aborda. A seguir, a segunda sessão traz o metodo de pesquisa, também abordado em dois subtitulos: os instrumentos resultados da pesquisa, utilizados. Na terceira sess.jo, sấo trazidos os resultados da pesquisa, que şొo demonstrados em tabelas as quais facilitam a compreensåo do leitor. A sess.jo seguinte traz a discussắo dos resultados e, na quinta e última sessắo, podemos ler as consideraḉes finais dos

Na introduçăo do artigo, os autores usam referèncias bibliográficas para explicar ao leitor o que seria o fenómeno bullying. No primeiro subtítulo, é abordada a questảo dos diferentes papej no cenário do bullying e como esses interagem entre si. No segundo subtitulg os autores trazem as diferenças entre os gêneros, e explicam os tipos de agressōes mais usadas por cada gênero.

Na segunda sessãgé explicado o método de pesquisa utilizado Aepe. é dividida em dois seboitulos: instrumentos pesquisa utilizado. instrumento de pesquisa, os alunos utilizaram um questionário; e sobre os procedimentos, sąo esclarecidas algumas questöes sobre como os

Versão 1- página 2

Ao lermos atentamente a primeira página de cada uma das duas versões é possível perceber duas preocupações: a) seguir o padrão sugerido para a escrita do texto; e b) realizar as correções de ordem sintática e morfológica: termos, pontuação, estrutura das frases.

No primeiro parágrafo, é possível visualizar a solicitação da profes- 
sora Liane: ${ }^{6}$ adição de um ponto e vírgula e de uma vírgula e supressão de um pronome, alterações que foram atendidas pela aluna Sara. No segundo parágrafo, há a adição de uma vírgula e a colocação em itálico da expressão bullying, ambos os movimentos sugeridos pela professora.

No terceiro parágrafo, diante do ponto de interrogação assinalado pela professora, a aluna suprime o segmento "uma ordem cronológica", substituindo o ponto por uma vírgula. A primeira modificação incide sobre o sentido da oração e ainda fica a dúvida se a aluna entendeu o que de fato quer dizer a expressão "cronológica." A segunda auxilia somente no encadeamento da oração.

Nesse mesmo parágrafo, a palavra "sessão" é assinalada três vezes e mantida pela aluna na segunda versão, o que marca a dificuldade de saber o motivo de realizar tal modificação e, por isso, a professora aponta a diferença entre "seção" e "sessão" na margem esquerda da segunda versão. Há uma outra questão relevante: como a aluna entende o sentido da expressão "na qual" e "a qual"? Pois ela suprime o "n" apenas diante da solicitação da revisora. Assim também ela insere as vírgulas solicitadas, as quais intercalam o adjunto adverbial "na quinta e última sessão".

No quarto parágrafo, há a repetição da preposição "para", circulada na correção, o que a aluna resolve através da supressão da segunda ocorrência e a adição de "a" junto ao "o" formando "ao leitor". A professora solicita a colocação de duas vírgulas para indicar adjunto adverbial no início da oração. Marca um ponto de interrogação próximo da expressão "os mesmos" e outro perto de "no qual". O primeiro caso é solucionado por Sara com a substituição pelo pronome "esses". O segundo caso é descartado pela aluna e substituído pela conjunção "e", revelando tratar-se de mais um movimento efetuado pelos autores do artigo e não de uma ação inserida em outra como poderia estar sugerido pelo uso de "no qual", o que parece sustentar a dificuldade de entendimento da significação do termo. Há a adição de um acento em "papéis".

No quinto parágrafo, o termo "sessão" continua sendo assinalado pela professora e mantido na segunda versão. Há um problema de regência em "é explicado sobre", o qual Sara resolve com a supressão de "sobre". Liane assinala a necessidade de perceber que o conector "onde" é inadequado. No entanto, o mecanismo de retomada sugerido pela aluna na segunda versão manteve-se inadequado. A necessidade de se rever a

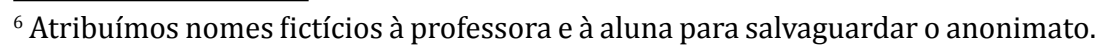


estrutura de um trecho foi resolvida com supressão. Já o questionamento referente à falha de concordância em "é esclarecido algumas questões", é resolvido com a substituição do verbo "ser" na terceira pessoa do singular pelo verbo "ser" na terceira pessoa do plural.

Atentemos para o seguimento da segunda página de cada texto.

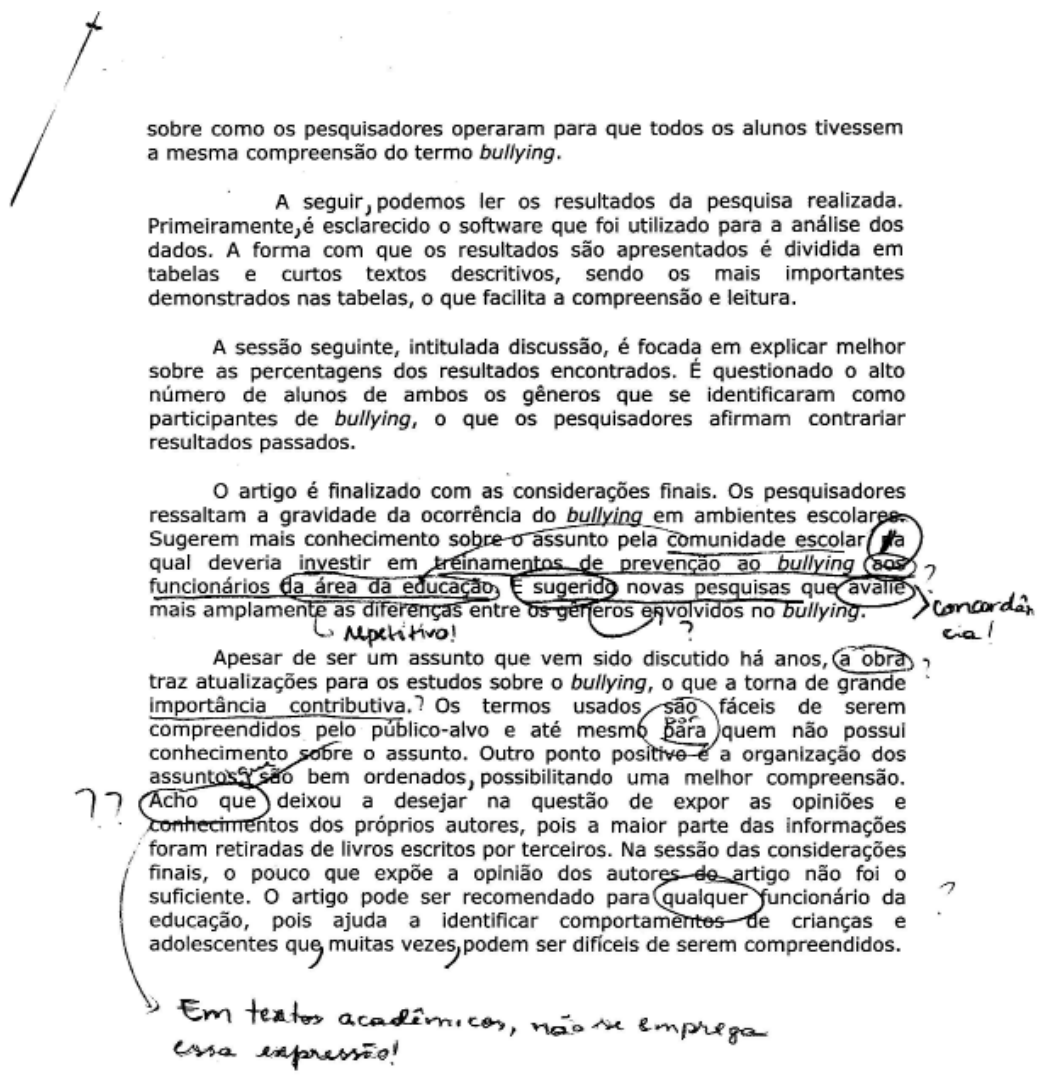

Versão 1 - página 2 
pesquisadores operaram para que todos os alunos tivessem a mesma compreensão do termo bullying.

A seguir, podemos ler os resultados da pesquisa realizada. Primeiramente, é esclarecido o software que fol utilizado para a análise dos dados. A forma com que os resultados são apresentados é dividida em tabelas e curtos textos descritivos, sendo os mais importantes demonstrados nas tabelas, o que facilita a compreensão e leitura.

A sessão seguinte, intitulada discussão, é focada em explicar melhor gebre as percentagens dos resultados encontrados. É questionado o alto número de alunos de ambos os gêneros que se identificaram como participantes de bullying, o que os pesquisadores afirmam contrariar resultados passados.

O artigo é finalizado com as considerações finais. Os pesquisadores ressaltam a gravidade da ocorrência do bullying em ambientes escolares. Sugerem mais conhecimento sobre o assunto pela comunidade escolar, a qual deveria investir em treinamentos de prevenção ao bullying. São sugeridas novas pesquisas que avaliem mais amplamente as diferenças entre os gêneros envolvidos no bullying.

O artigo é de grande importância, pois tráz atualizações no estudo sobre o bullying. Apesar de ser um assunto que vem sido discutido há anos, existe, ainda, e sempre existirá, uma grande necessidade de novas pesquisas no assunto, pois sofre constantes mudanças, de acordo com a época e cultura. Os termos utilizados são fáceis de serem compreendidos pelo público-alvo e até mesmo por quem não possui conhecimento sobre o assunto. Outro ponto positivo é a organização, os assuntos são bem ordenados, possibilitando uma melhor compreensão. 0 artigo pode ser

7 recomendado a todos os funcionários? da área da educação, pois ajuda a identificar comportamentos de crianças e adolescentes que, muitas vezes, podem ser difíceis de serem compreendidos.

Versão 2 - página 2

No sexto parágrafo, Liane solicita a adição de duas vírgulas na segunda versão antes de adjuntos adverbais, as quais são inseridas pela aluna na segunda versão.

No sétimo parágrafo, há novamente a insistência para a correção de "sessão". Também é feito um traço na expressão "sobre" para que seja suprimida, mas ambas são realizadas somente na segunda versão, uma vez que tais correções já haviam sido mencionadas anteriormente. Essa manutenção tem relação direta com a aparente dificuldade de compreensão das razões para tais alterações, outrora já questionadas pela revisora.

No oitavo parágrafo, são assinaladas as expressões "comunidade escolar" e "da área da educação", que são ligadas por um traço indicativo de relação. Sara soluciona o problema de sentido expresso pela repetição das ideias através da supressão da segunda. A aluna também atenta para as expressões circuladas e com indicação de problemas de concordância. 
Ela substitui "É sugerido" por "São sugeridas" e "avalie" por "avaliem" a fim de ajustar a concordância com o sujeito da oração.

O nono e último parágrafo é o que apresenta o maior número de interferências da educadora e foi o que mais suscitou modificações na segunda versão. Antes da primeira oração desse parágrafo, foi adicionada uma outra na segunda versão: "O artigo é de grande importância, pois traz atualizações no estudo sobre o bullying". A professora pede novamente que o último termo "bullying" seja colocado em itálico na segunda versão assim como Sara havia feito na primeira. Parece ser a inserção desse período a solução encontrada por Sara para o estranhamento de Liane diante do emprego de "obra" para referir-se ao "artigo" e do emprego de "importância contributiva".

Ainda nesse parágrafo, o primeiro período é deslocado e passa a ser a segunda oração e é acrescido de novas ideias: "Apesar de ser um assunto que vem sido discutido há anos, existe, ainda, e sempre existirá, uma grande necessidade de novas pesquisas no assunto, pois sofre constantes mudanças, de acordo com a época e com a cultura." As vírgulas em destaque foram sugeridas na segunda versão.

Na oração iniciada por "Os termos usados são fáceis" ocorre a primeira modificação sem interferência da revisora: a aluna substitui "usados" por "utilizados". A professora pede a substituição de "para quem" por "por quem", que é devidamente realizada pela estudante. Também chama a atenção os movimentos na oração "Outro ponto positivo é a organização dos assuntos, são bem ordenados,..." em que há a sugestão, na primeira versão, da inserção de um "que" antes do verbo ser e da vírgula após "ordenados", uma vez que a aluna resolve de maneira diferente: ela não insere o pronome relativo "que" e prefere formar uma nova oração: "Outro ponto positivo é a organização, os assuntos são bem ordenados, possibilitando uma melhor compreensão." A oração iniciada por "Acho que" foi simplesmente suprimida, movimento que exigiria bastante reflexão junto aos alunos acerca da autoria em seus textos. Há uma oração um tanto quanto confusa que a própria aluna decide suprimir: "Na sessão das considerações finais, o pouco que expõe a opinião dos autores do artigo não foi o suficiente."

A supressão, nesses casos, parece configurar uma maneira imediata de solucionar o problema em vez de retomar o período e ressignificá-lo.

No último período do parágrafo, a aluna insere duas vírgulas sugeridas por Liane para intercalar a expressão "muitas vezes", mas não 
consegue resolver adequadamente a colocação de "qualquer" na primeira versão, pois ao substituir por "a todos os funcionários", ainda não ficou clara a delimitação de para quem o artigo é realmente recomendado.

Diante de tamanha dificuldade em projetar o endereçamento de seu texto, é possível perceber que, embora haja interferência do professor, que poderia provocar o deslocamento do endereçamento do texto a outros leitores, não há demonstração de troca que efetive essa ressignificação. 0 que acabamos por encontrar são modificações que não acarretam em implicações significativas para o sentido do texto.

Agustini et al (2013) elucida a projeção de (inter)locutor que se coloca em tela, na escrita, uma vez que há dizeres "atribuídos" a outros, que funcionam na textualidade da escrita, de modo que, ao (se) enunciar, o locutor faz outros locutores (se) dizerem. Para os autores, ancorados nos pressupostos benvenistianos, há uma coenunciação em funcionamento na escrita. No caso da escrita em âmbito universitário, portanto, o aluno acaba por, no processo, elaborar o seu texto sob a insígnia do discurso pedagógico em jogo.

Mesmo com a insistência da professora com relação a pensar sobre o alocutário durante as aulas, os alunos demonstraram muita dificuldade em encontrar como e a quem recomendar a resenha. Isso é perceptível em vários textos do corpus e, muitas vezes, compromete o sentido do texto como um todo, interferindo no processo de sintagmatização para que o scriptor semantize e então construa sentidos. Se o alocutário não está claro, evidentemente a emergência da subjetividade e a constituição dos sentidos ficam comprometidas.

Ao se produzir duas versões, muito do processo não pode, infelizmente, ser visualizado. Obviamente não há como resgatar toda a enunciação, pois cada ato enunciativo se perde assim que proferido e já é re-significado na próxima vez. É possível perceber as marcas desse processo nas versões, mas de forma um tanto quanto oculta, pois o traço da professora, muitas vezes, fica mais evidente do que a do estudante. É válido, porém, o exercício daquele que corrige de atentar para a primeira versão produzida a fim de valorizar os movimentos dos alunos, de melhor avaliá-los. Tratase de uma tentativa interessante de permitir que o aluno re-invente o seu dizer na troca (inter)subjetiva com o professor, ainda que se $r$-inventar na própria escrita dependa de compreender o seu papel e de querer fazer sentido para um determinado público. 


\section{Palavras finais}

O estabelecimento de laço entre professor e aluno na escrita não é tarefa fácil porque pressupõe um alto grau de alinhamento e de acolhimento da escrita desse aluno e da compreensão da complexidade desse processo. Reconhecemos, no entanto, na professora-revisora, uma tentativa de efetuar esse laço, ainda que a amarra não tenha sido de todo efetivada.

Acreditamos, contudo, que a análise do processo constitui uma chave importante para, aos poucos, o aluno sentir-se motivado a ampliar o endereçamento dos textos. Para tanto, o professor pode e deve problematizar o processo de escrita de seus alunos junto a eles, fazendo com que, por meio da reescrita, possam ressignificar a si mesmos e a sua maneira de estar na língua. Por fim, podemos dizer que o laço é um ponto fundamental a ser observado, pois à medida que o professor atua como mediador e problematizador do texto do aluno, ele acaba concedendo-lhe um novo lugar de enunciação, permitindo-lhe apropriar-se do texto como espaço de reinvenção.

\section{Referências}

AGUSTINI, C.L.H. et al. Rasuras em manuscritos escolares e implicações enunciativas: da projeção da (inter)locução à transmissibilidade. In: Letras \&Letras, v.29, n.1, 2013, p.1-20.

ARAÚJO, É. D. Implicações subjetivas na relação professor-aluno: um olhar sobre o processo de (re)escrita de manuscritos escolares. 2014, 211f. Dissertação (Mestrado) - Curso de Linguagem, Texto e Discurso, Instituto de Letras e Linguística, Universidade Federal de Uberlândia, Uberlândia, 2014. Disponível em: <http:// repositorio.ufu.br/handle/123456789/4129>. Acesso em: 13 abr. 2014.

ARESI, F. Os índices específicos e os procedimentos acessórios da enunciação. ReVEL,

v.9, n.16, 2011. Disponível em: <http://www.revel.inf.br/files/artigos/revel_16_ os_indices_especificos.pdf>. Acesso em: 17 maio 2015.

BENVENISTE, É. A forma e o sentido na linguagem (1966). In: BENVENISTE, É. Problemas de Linguística Geral II. Campinas: Pontes, 2006a.

. A linguagem e a experiência humana (1965). In: BENVENISTE, É. Problemas de linguística geral II. Campinas: Pontes, 2006b.

. A natureza dos pronomes (1956). In: BENVENISTE, É. Problemas de Problemas de linguística geral I. Campinas: Pontes, 2005a. 
BENVENISTE, É. Da subjetividade na linguagem (1958). In: BENVENISTE, É. Problemas de Problemas de linguística geral I. Campinas, SP: Pontes, 2005b

. Estrutura das relações de pessoa no verbo (1946) In: BENVENISTE, É. Problemas de linguística geral I. Campinas: Pontes, 2005c.

. O aparelho formal da enunciação (1970). In: BENVENISTE, É. Problemas de linguística geral II. Campinas: Pontes, 2006c.

. Semiologia da Língua (1969). In: BENVENISTE, É. Problemas de linguística geral II. Campinas: Pontes, 2006d.

. Vista d'olhos sobre o desenvolvimento da linguística (1963). In: BENVENISTE, É. Problemas de linguística geral I. Campinas: Pontes, $2005 \mathrm{~d}$.

. Dernières Leçons. Paris: Editora Gallimard, 2012, 210f. Resenha de Agustini et al. Resenha. Revista Línguas e instrumentos linguísticos, jul./dez. 2012.

CAPT, V. Poétique des écrits bruts. Limoges: Éditions Lambert-Lucas, 2013.

DESSONS, G. Une antropologie du langage. In: DESSONS, G. Émile Benveniste, l'invention du discours. Paris: Editions In Press, 2006, p.41-55.

DUFOUR, D-R. Os mistérios da trindade. Rio de Janeiro: Companhia de Freud, 2000.

FENOGLIO, I. Déplier l'écriture pour re-lire l'article publié. Les manuscrites de «L'appareil formel de l'énonciation» d'Émile Benveniste. In: BRUNET, Émilie; MAHRER, Rudolf. Relire Benveniste: réceptions actuelles des Problèmes de linguistique générale. Bruxelles: Academia, coll.» Sciences du langage: carrefours et points de vue», n.3, 2011, p.263-265; p.275-277

FLORES, V. N. Sujeito da enunciação: singularidade que advém da sintaxe da enunciação. DELTA [on-line], 2013. Disponível em: <http://www.scielo.br/pdf/delta/ v29n1/05.pdf>. Acesso em: 16 abr.2015.

FLORES, V. N.; TEIXEIRA, M. As perspectivas para o estudo das formas complexas do discurso: atualidades de Émile Benveniste. ReVEL, edição especial n.7, 2013.

MELLO, V. H. D. A sintagmatização-semantização: uma proposta de análise de texto. 2012. 145 f. Tese (Doutorado) - Programa de Pós-Graduação em Letras, Instituto de Letras, Universidade Federal do Rio Grande do Sul, Porto Alegre, 2012. Disponível em: <http://www.lume.ufrgs.br/bitstream/handle/10183/56031/000858559. pdf?sequence=1>. Acesso em: 27 abr. 2015.

NORMAND, C. Leituras de Benveniste: algumas variantes sobre um itinerário demarcado. Porto Alegre. Letras de Hoje, v.44, n.1, p.12-19, jan./mar. 2009. Disponível em: <http://revistaseletronicas.pucrs.br/ojs/index.php/fale/article/viewFile/5647/4115>. Acesso em: 4 maio 2015.

NUNES, P. Á. A prática tradutória em contexto de ensino (re)vista pela ótica enunciativa. 2012, 239f. Tese (Doutorado) - Programa de Pós-Graduação em Letras, Instituto de Letras, Universidade Federal do Rio Grande do Sul, Porto Alegre, 2012. Disponível em: <http://www.lume.ufrgs.br/bitstream/handle/10183/55982/000858935.pdf?sequence=1>. Acesso em: 9 mar. 2015. 
ROCHA, L. C. P. Um olhar enunciativo para interlocuções entre médico e paciente em consultas ambulatoriais pelo Sistema Único de Saúde. 2014, 95f. Dissertação (Mestrado) - Curso de Linguística Aplicada, Unidade Acadêmica de Pesquisa e Pós-Graduação, Universidade do Vale do Rio dos Sinos, São Leopoldo, 2014. Disponível em: <http://biblioteca.asav.org.br/vinculos/00000A/00000AA4.pdf>. Acesso em: 5 maio 2015.

TEIXEIRA, M. O estudo dos pronomes em Benveniste e o projeto de uma ciência geral do homem. Desenredo. Revista do Programa de Pós-Graduação em Letras da Universidade de Passo Fundo, v.8, n.1, p.71-83, jan./jun. 2012. 